true (there are almost no data to date), then the degree of dispersal and gene flow between reefs will be critical in determining the overall genetic variability of coral species. These issues must be more fully explored in order to predict the evolutionary consequences of coral life histories and to attempt the long-term management of these diverse communities.

\section{A:knowledgements}

We thank R. Babcock, V. Hall, 1. Tanner, B. Willis, and members of the Coral Discussion Group at James Cook University for valuable suggestions and criticisms. This paper was prepared with support fram the US National Science Foundation (I.H.C. and T.P.H.), the National Geographic Society (T.P.H.) and the Australian Research Council (D.J.A. and T.P.H.).

\section{R.eferences}

1 Connell, J.H. (1978) Science 199,

1302-1310

2 Rosen, B.R. (1981) in Chance, Change and Challenge: The Evolving Biosphere

('Greenwood, P.H. and Florey, P.L., eds), pp.

03-129, British Museum (Natural History)

and Cambridge University Press

3 Hughes, R.N. (1989) A Functional Biology of Clonal Animals, Chapman $E$ Hall 4 Rosen, B.R. (1990) in Palaeobiology: A Synthesis (Briggs, D.R. and Crowther, P.R., eds). pp. 330-335. Blackwell

5 Harrison, P.L. and Wallace, C.C. (1990) in Ecosystems of the World, Vol. 25: Coral Reefs (Dubinsky, Z., ed.), pp. 133-208,

Eisevier

6 Lang, I.C. and Chornesky, E.A. (1990) in Ecosystems of the World, Vol. 25: Coral Reefs (Dubinsky, Z., ed.), pp. 209-252, Elsevier

7 Buss, L.W. (1987) The Evolution of Individuality, Princeton University Press 8 Rinkevich, B. and Weissman, I.L. (1987) Symbiosis 4, 117-134

9 Hidaka, M. (1985) Coral Reefs 4, 111-116 10 Resing, J.M. and Ayre, D.J. (1985) Proc 5th Int. Coral Reef Symp. Tahiti 6, 75-81 11 Hughes, T.P. and Jackson, J.B.C. (1985) Ecol. Monogr. 55, 141-166

12 Wahle, S.M. (1985) Bull. Mar. Sci. 37, 905-927

13 Bak, R.P. and Van-Es, Y.S. (1980) Bu/l Mar. Sci. 30, 883-887

14 Stoddart, J.A. (1984) Mar. Biol. 81, 19-30 15 Ayre, D.J. and Willis, B.L. (1988)

Mar. Biol. 99, 495-505

16 Palumbi, S.R. (1992) Trends Ecol. Fvol. 7 , 114-118

17 Palumbi, S.R. and Kessing, B.D. (1991) Evolution 45, 1790-1801

18 Highsmith, R.C. (1982) Mar. Ecol. Prog Ser. 2, 207-226

19 Hughes, T.P. (1984) Am. Nat. 123,
778-795

20 Done; T.J. (1987) Coral Reefs 6, 75-90

21 Caswell, H. (1989) Matrix Population Models, Sinauer

22 Lasker, H. (1990) Ecology 71, 1578-1589

23 Cotteli, N.J. (1991) Ecology 72, 457-467

24 McFadden, C.S. $(1991)$ Ecology 72.

1849-1866

25 Babcock, R.C. (1984) Coral Reefs 2,

187-195

26 Caswell, H. (1985) in Population Biology and Evolution of Clonal Organisms (Jackson,

I.B.C., Buss, L.W. and Cook, R.E., edsi, pp.

187-224, Yale University Press

27 Karlson, R.H. (1988) Ecology 69,

1219-1232

28 Jackson, J.B.C. (1986) Bull. Mar. Sci. 39,

588-606

29 Jokiel, P.L. (1990) Nature 347, 665-667

30 Sammarco, P.W. and Andrews, I.C. (1988)

Science 239, 1422-1424

31 Willis, B.L. and Oliver, J.K. (1990)

Ophelia 32, 145-162

32 Ayre, D.J. (1990) Bull. Ecol. Soc

Am, 71,81

33 Ayre, D.J., Veron, J.E.N. and Dufty, S.L.

(1991) Coral Reefs 10, 13-18

34 Heyward, A.J, and Babcock, R.C. 11986

Mar. Biol. 90, 191-195

35 Szmant, A.M. (1986) Coral Reefs 5, 43-53

36 Potts, D.C. (1984) Paleobiology 10, 48-58

37 Hughes, T.P. and Connell, I.H. (1987)

Am Nat $129,818-829$

38 Babcock, R.C. 119911 Ecol Monogr. 61 ,

$225-244$
The use of tetracycline over the past few decades has been accompanied by a drastic increase in the frequency of tetracycline resistance in a wide range of bacterial species and genera. A diversity of resistance determinants is found in the microbial world, coding for markedly different mechanisms of resistance. The recent analysis of one family of resistance determinants provides evidence for intergenic and intragenic coevolutionary changes as well as for an unusual evolutionary history of duplication and divergence in function of domains within a single locus.

Of the dozens of antibiotics on the market today, tetracycline is produced on the greatest scale. For example, in 1983 (the last date for which data are freely available), the total annual production of tetracyclines in the USA was 3.86 million $\mathrm{kg}$, constituting $22 \%$ of

Rebecca lohnson and Julian Adams are at the Dept of Biology, University of Michigan, Ann Arbor, MI 48109-1048, USA.

\title{
The Ecology and Evolution of Tetracycline Resistance
}

\section{Rebecca Johnson and Julian Adams}

the total annual antibiotic production for that year'. However, less than half of the tetracycline production was destined for the treatment of infectious disease; some $71 \%(2.73$ million $\mathrm{kg})$ was added to animal feed at subtherapeutic levels to stimulate weight gain ${ }^{2}$ (a practice long since banned in Europel, as well as for the prophylactic control of disease'. Tetracyclines appear to be quite stable in the environment, and typically are not broken down by resistant strains, unlike other antibiotics such as ampicillin. No decrease in tetracycline activity was found in samples of human and rodent feces stored at room temperature for several months ${ }^{3}$. Environmental contamination by tetracyclines may therefore have a cumulative impact.
Epidemiology of tetracycline resistance

The rapid evolution and spread of antibiotic-resistant strains of pathogenic bacteria have been well-documented ${ }^{4}$, and it is therefore not surprising that the percentage of coliform bacteria, isolated from human and animal hosts, expressing resistance to tetracycline is extremely high. In 1985, $12 \%$ of all strains of Escherichia coli isolated from healthy humans residing in Boston, USA, were resistant to tetracycline, while the percentage of tetracycline-resistant strains isolated from farm animals during the same period ranged between $71 \%$ and $93 \%$ (Table 1). Resistance determinants found in one genus are sometimes found later in others, often differing dramatically in type and ecological location. For example, tetracycline 
Table 1. Prevalence of tetracycline resistance in bacteria isolated from various hosts in the USA

\begin{tabular}{lllrr} 
Host & Period & Region & $\begin{array}{r}\text { Total no. } \\
\text { of isolates }\end{array}$ & $\begin{array}{c}\text { Tetracycline } \\
\text { resistance (\%) }\end{array}$ \\
Humans (hospital) & 1986 & Boston & 3757 & 26 \\
Humans (hospital) & $1971-1982$ & USA & 1800000 & 28 \\
Humans (community) & 1985 & Boston & 388 & 12 \\
Animal & 1980 & USA & 100 & 80 \\
Pigs & 1974 & Illinois & 530 & 90 \\
Pigs & $1981-1987$ & South Dakota & 1015 & 96 \\
Pigs & $1985-1986$ & Texas & 107 & 93 \\
Pigs & $1986-1987$ & Georgia & 405 & 93 \\
Cattle & 1974 & Illinois & 106 & 49 \\
Cattle & $1981-1987$ & South Dakota & 366 & 76 \\
Cattle & $1985-1986$ & Texas & 405 & 71 \\
Cattle & $1986-1987$ & Georgia & 265 & 57 \\
Poultry & $1981-1987$ & South Dakota & 30 & 83 \\
\hline
\end{tabular}

aData from Ref. 1.

resistance plasmids first isolated from staphylococci have been picked up subsequently in strains of Bacillus, and plasmid exchange has also been reported between streptococci and strains of Lactobacillus and Listeria ${ }^{5}$. The list of bacterial species in which tetracycline resistance has been detected is now long and includes both Gram-positive and Gram-negative bacteria, some of which are not commensals of humans or animals $s^{6,7}$.

The existence of significant levels of tetracycline in the microbial environment generates strong selective pressures for resistant strains. In one study, the frequency of tetracycline-resistant bacteria isolated from chickens fed tetracycline-supplemented feed increased from about $0 \%$ to about $100 \%$ within one week ${ }^{8}$. Within five to six months, tetracycline-resistant organisms were isolated from workers on the same farm; $31 \%$ of their fecal samples contained more than $80 \%$ tetracycline-resistant organisms as compared to $6.8 \%$ of the samples from neighbors?. As with many other antibiotic-resistance determinants ${ }^{4}$, this spread of tetracycline resistance could be linked to the presence of genes conferring resistance to tetracycline located on plasmids - extrachromosomal circular DNA elements that replicate independently of the bacterial chromosome and that are capable of transmitting themselves from cell to cell and even across species boundaries. While plasmids may be the actual messengers, the antibiotic-resistance genes are frequently associated with moveable genetic elements, or transposons, located on the plasmids. These transposons may allow the transfer of drug-resistance genes from the plasmids, which are often dispensable, to the bacterial chromosome, which is clearly not ${ }^{10}$.

Although laboratory studies have shown that the expression of tetracycline resistance is selected against in the absence of the drug ${ }^{11-13}$, tetracycline resistance is surprisingly persistent in the microbial flora of farm animals, even years after the discontinuance of tetracycline supplementation in animal feed ${ }^{14}$. This phenomenon may be attributed to the persistence of tetracycline in the ecosystem ${ }^{3}$ and/or to the evolution of strains in which the intrinsic deleterious effect of tetracycline resistance has been attenuated ${ }^{14,15}$.

\section{Genetics of tetracycline resistance}

The promiscuous transfer of genetic information may potentially explain the wide dissemination of tetracyclinc-resistance factors, but does it mean that all are descended from one primordial resistance gene? All of the evidence accumulated to date suggests that this is not the case, and that there exists a great diversity of determinants for tetracycline resistance.

Three major families of tetracycline-resistance determinants have been specified on the basis of their mechanism of resistance, DNA homology between the determinants and level of resistance to tetracycline ${ }^{16}$. Two of these families code for an active efflux system whereby the antibiotic is pumped out of the cell. One of these two families is found in Gram-negative organisms, including such genera as Escherichia, Hemophilus and Aeromonas ${ }^{17}$, whereas the second family is found in Gram-positive aerobic organisms ${ }^{18}$. A third family is notable not only for its completcly different mechanism of action, but also for its wide dissemination among distantly related bacteria. Members of this family mediate resistance by protecting ribosomes from the inhibitory action of tetracyclines. (Tetracycline acts by preventing tRNA molecules from binding to the ribosomes during peptide elongation.) The tet $M$ determinant of this third family is found in such diverse organisms as the Gram-positive streptococci, Gramnegative species such as Neisseria as well as the cell-wall-free mycoplasmas, and species of uncertain taxonomic status ${ }^{19}$. The frequent location of tet $M$ determinants on conjugative transposons (transposable elements which possess the ability to transfer themselves from cell to cell, even across species boundaries) may account for their broad dissemination ${ }^{19}$. A number of other tetracycline resistance determinants have been described. Some of these may belong to one of these three families, while others almost certainly define new ones ${ }^{17}$ with different mechanisms of action, such as the enzymatic inactivation of tetracycline ${ }^{20}$

\section{Origin of tetracycline-resistance determinants}

The use of tetracyclines in a medical and veterinary context has been quite recent, yet tetracyclineresistance factors have been de tected in strains isolated long before the widespread use of tetracycline by humans, as well as in strains isolated from remote parts of the world where antibiotic therapy is unknown ${ }^{7}$. Tetracyclines are naturally produced by members of the genus streptomyces, which have been shown to possess tetracycline-resistance determinants be longing to the first two families ${ }^{21}$. A popular theory holds that tetracycline-resistance determinants originated in such organisms, and were disseminated by interspecies transfer mediated by a variety of agents including plasmids ${ }^{7.17}$, conjugative transposons ${ }^{19}$, and bacteriophages ${ }^{5}$, as well as by transformation with naked DNA. The discovery that cryptic tetracycline- 
resistance determinants are present in the chromosomes of Bacteroides $^{22}$, E. coli ${ }^{23}$ and Bacillus subtilis ${ }^{24}$ suggests additional, albeit unknown functions of such sequences.

Since so many distinct tetracycline-resistance determinants are being discovered, Levy ${ }^{17}$ has suggested that tetracycline resistance has been evolving over millions of vears, perhaps in response to competition with organisms that produce compounds similar to tetracycline.

\section{Evolution of a tetracycline-resistance amily}

Expression of tetracycline resistance in members of the first family of determinants, found in Gramnegative organisms, is regulated in much the same way as the lac operon In the absence of tetracycline, but not in its presence, a repressor protein binds to the operators and prevents transcription. All members of this family show the same pattern of genetic organization (Fig. 1), comprising a structural gene and a repressor gene that are expressed divergently from overlapping promoters ${ }^{24}$. In the region between the two genes are two palindromic sequences thought to act as operators ${ }^{25}$ (DNA binding regions for the protein repressor) Within this family there are five classes (A-E), which can be dis tinguished by degree of DNA sequence similarity, and which differ in their levels of resistance to tetracycline $^{16}$. Differentiation between some classes is so high that little DNA-DNA hybridization occurs, even under 'low stringency' conditions (which allow for some mismatching). At the amino acid level, identity between the classes ranges from $43 \%$ to $63 \%$ for the repressor protein $^{26}$, and $45 \%$ to $78 \%$ for the structural gene product ${ }^{27}$ (Table 2).

The functional significance of these differences is suggested by in vitro studies designed to measure the ability of a particular repressor molecule to bind to various operators, and thereby repress transcription. For example, repressor molecules from class B were unable to repress transc-iption of class $A$ and $C$ genes but could weakly repress transcription of class D genes ${ }^{28}$. Thus, there is evidence that the differentiation between the classes has involved coevolutionary changes in the repressor protein and the operator regions. All of the evidence so far assembled indicates that classes $A$ and $C$ are closely related and can be considered to lie on one branch of an evolutionary lineage, $B$ and $D$ on another, with class $E$ possibly on a third.

Additional information on the phylogenetic relationship between the classes is provided by the structural coding regions of members of family $\mathrm{l}$. This region has been the subject of intensive analysis in the last ten years by Levy's group, as well as by others. It is now known that the structural coding region of the tetracyclineresistance operon of the transposon $\mathrm{Tn} 10$ (belonging to class $\mathrm{B}$ ) contains a single open reading frame coding for a protein approximately $42 \mathrm{kDa}$ ( 399 amino acids) in size. This region is unusual in that two complementing groups, designated tet $A$ and tetB, lie within it. Thus, deletion mutations in the tet $A$ region complemented tet $B$ region point mutations, resulting in significant levels of tetracycline resistance ${ }^{29}$. All complementing strains showed active efflux of tetracycline from the cell, but not as efficiently as that in wild-type cells. Although the complementation data point to the existence of two structural genes for tetracycline resistance, only one protein product has been detected, and mutations in both the tet $A$ and tet $B$ regions affect this protein product. Designated TET, it is now known to be a membrane-spanning protein that mediates tetracycline efflux ${ }^{18}$.

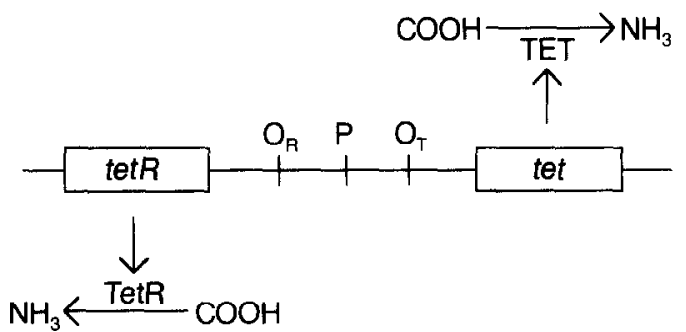

Fig. 1. Structure of a tetracycline-resistance operon belonging to family 1 . Open rectangles, tetR and tet, represent the genes encoding tetracycline-repressor and tetracycline-resistance proteins, respectively. Vertical lines represent overlapping regulatory sequences with palindromic operators, $\mathrm{O}_{k}$ and $\mathrm{O}_{\mathrm{p}}$, and promoter, $\mathrm{P}$ Horizontal arrows indicate that the tet $R$ and tet genes are transcribed in opposite directions; the $\mathrm{N}$ - and C-terminal ends of the TetR and TET proteins are shown.

The tet $A$ and tet $B$ regions, therefore, define intragenic (rather than the more conventional intergenic) complementation regions, and they may be considered to represent two structural domains, designated $\alpha$ and $\beta$, of the TET protein ${ }^{30}$.

The $\alpha$ and $\beta$ domains correspond approximately to the $\mathrm{N}$ - and $\mathrm{C}$-terminal halves of the TET protein, respectively. By engineering interdomain hybrid tet genes with $\alpha$ and $\beta$ domains from members of different classes of family I, Rubin and Levy were able to gain insight into the molecular evolution and function of the $\alpha$ and $\beta$ domains ${ }^{31}$. Using conventional cloning techniques, hybrid tetracycline-resistance genes were constructed containing different combinations of the $\alpha$ and $\beta$ domains from classes $A$ and $C$, and the levels of resistance to tetracycline were measured in an $E$. coli host strain. In all cases a wild-type repressor gene and operator region were included in the plasmid from the same class as that of the $\alpha$ domain. Only combinations of the $\alpha$ and $\beta$ domains from classes $A$ and $C$ (which are $78 \%$ identical) generated an active

\begin{tabular}{|c|c|c|c|c|}
\hline \multirow[b]{2}{*}{$\begin{array}{l}\text { Classes } \\
\text { compared }\end{array}$} & \multicolumn{2}{|c|}{ Repressor protein } & \multicolumn{2}{|c|}{ Structural protein } \\
\hline & $\begin{array}{c}\text { Nucleotide } \\
\text { homology } \\
(\%)\end{array}$ & $\begin{array}{c}\text { Amino acid } \\
\text { homology } \\
(\%)\end{array}$ & $\begin{array}{c}\text { Nucleotide } \\
\text { homology } \\
(\%)\end{array}$ & $\begin{array}{c}\text { Amino acid } \\
\text { homology } \\
(\%)\end{array}$ \\
\hline $\begin{array}{l}A, C \\
B, D\end{array}$ & $\begin{array}{l}61.5 \\
58.3\end{array}$ & $\begin{array}{l}58.8 \\
63.3\end{array}$ & 74.0 & 78.3 \\
\hline$A, B$ & 44.4 & 43.5 & 48.0 & 45.1 \\
\hline$C, D$ & 48.5 & 43.6 & & \\
\hline$B, C$ & 44.3 & 44.9 & & \\
\hline$A, D$ & 50.6 & 44.4 & & \\
\hline
\end{tabular}

${ }^{a}$ Data from Refs 26 and 27. 
Table 3. Relative tetracyclineresistance levels ${ }^{\mathrm{a}}$

\begin{tabular}{|c|c|}
\hline $\begin{array}{l}\text { Class origin of } \\
\text { tet } A \quad \text { tet } B\end{array}$ & $\begin{array}{c}\text { Resistance } \\
\text { level (\%) }\end{array}$ \\
\hline $\begin{array}{l}A \\
B \\
C\end{array}$ & $\begin{array}{l}100 \\
82 \\
50\end{array}$ \\
\hline $\begin{array}{l}\mathrm{C} \\
\mathrm{C} \\
\mathrm{B}\end{array}$ & $\begin{array}{l}54 \\
<1 \\
<1 \\
<1\end{array}$ \\
\hline
\end{tabular}

${ }^{a}$ Data from Ref. 31.

efflux protein (Table 3); combinations of domains from classes $B$ and $C$, which show much less identity $(45 \%)$, were inactive ${ }^{31}$. Thus, coevolutionary changes can also be seen between the $\alpha$ and $\beta$ domains of the TET resistance protein.

The highly specific interactions between the $\alpha$ and $\beta$ domains of the TET protein are especially intriguing. Recent work from Levy's group has shown that a functional efflux protein may exist even when the $\alpha$ and $\beta$ domains are present on different molecules $^{32}$. For example, strains expressing the $\alpha$ and $\beta$ domains from classes $B$ and $C$ on separate polypeptides showed levels of tetracycline resistance equal to, or even greater than, those of strains with full-length hybrid molecules. The curious ability of the $\alpha$ and $\beta$ domains to behave as separate polypeptides, even though they interact specifically and are components of a single polypeptide chain, explains the confusion in the early 1980s concerning the number of structural resistance genes encoded by the tetracyclineresistance operons belonging to family $\mathbf{1}^{29,30,33}$. It should be no surprise, therefore, that analysis of the nucleotide and amino acid

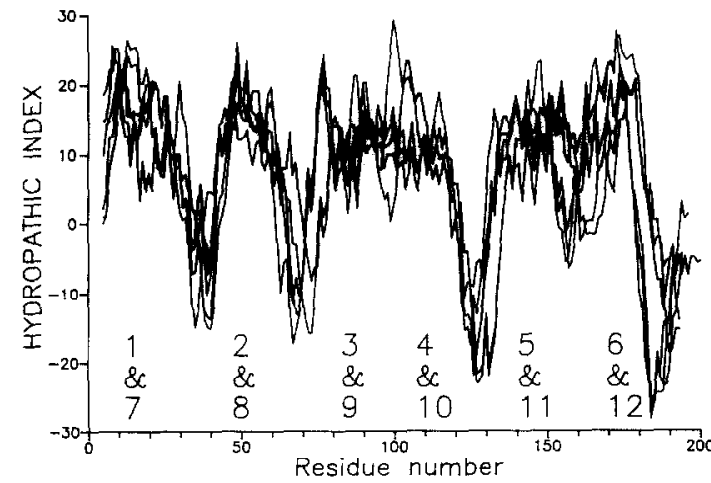

Fig. 2. Overlay of hydropathy plots for the $\mathrm{N}$ - and C-terminal halves ( $\alpha$ and $\beta$ domains) of TET proteins from classes $A, B$ and $C$. The predicted hydropathic regions transmembrane helicesl are numbered 1-12. Reproduced from Ref. 34, with permission. sequences of these two domains provides strong evidence for their origin from a common ancestor ${ }^{34}$.

In common with other membrane proteins, the TET protein $(\sim 400$ amino acids) exhibits a number of hydropathic segments interspersed with hydrophilic regions. Twelve such hydropathic regions of $20-25$ amino acids in length exist in the TET protein. There is good evidence that these regions span the bacterial membrane, and are particularly important in the active transport of tetracycline out of the cell. When the $\alpha$ and $\beta$ domains (each 200 amino acids in length) are compared, a striking similarity is demonstrated. Not only does each domain possess exactly six hydropathic regions, but the distribution of regions of hydropathy is very similar between domains for classes A-C (Fig. 2). Statistical tests of similarity between the $\alpha$ and $\beta$ domains were highly significant and could not be explained by the spurious occurrence of unrelated membranespanning sequences in both domains. Assuming a normal distribution of sequence similarity scores, the probability that the sequences are unrelated varied between 0.03 and $<0.0001$ (Ref. 34). Within the two domains an even higher level of similarity is seen between a core sequence of 107 amino acids. It appears, therefore, that the TET protein has its origins in a tandem duplication of a coding sequence expressing a hydrophobic membrane protein of about 200 amino acids. Coevolutionary changes have resulted in divergence within each of the tandem segments, preferentially near the ends of each unit ${ }^{34}$. Since functional versions of both domains are required for expression of tetracycline resistance, the domains have evolved complementary functions, while maintaining structural and sequence similarities.

Although many tetracyclines are naturally occurring chemicals, our detailed knowledge of the ecology and evolution of tetracycline resistance is the result of their widespread use in medicine and agriculture. The present-day wide dissemination of tetracycline-resistance determinants necessarily attenuates their value in the treatment of infectious disease. From a public-health standpoint perhaps the most important lesson to be learned from these studies is to avoid the misuse and overuse of other antibiotics to which pathogenic microorganisms have not yet developed widespread resistance 3 .

\section{Acknowledgement}

We thank S.B. Levy for helpful discussion, and R.B. Helling, E. Pichersky, R.F Rosenzweig and $E$. Werner for helpful comments on early drafts of the manuscript. The preparation of this review was supported in part by US Public Health Service grant GM30959

\section{References}

1 Swartz, M.N. et al (1989) Human Health Risks with the Subtherapeutic Use of Penicillin or Tetracyclines in Animal Feed: Study Report, Institute of Medicine. National Academy Press 2 Gustafson, R.H. and Kiser, J.S. (1985) in The Tetracyclines (Hlavka, I.I. and Boothe, I.H. eds), pp. 405-446, Springer-Verlag 3 Levy, S.B. (1982) Lancet ii, 83-88 4 Falkow. S. (1975) infectious Multiple Drug Resistance, Pion Press

5 Levy, S.B. (1975) in Engineered Organisms in the Environment: Scientific Issues (Halvorson,

H.O., Pramer, D. and Rogul, M., eds), pp 180-190, American Society of Microbiology 6 Levy, S.B. (1984) in Antimicrobial Drug Resistance (Bryan, L.E., ed.), pp. 191-240 Academic Press

7 Chopra, I. (1985) in The Tetracyclines (Hlavka, I.) and Boothe, J.H., eds), pp. 317-392, Springer-Verlag

8 Levy, S.B. (1986) in Antibiotic Resistance Genes: Ecology Transfer and Expression (Levy, S.B. and Novick, R.P., eds), pp. 17-30, Cold Spring Harbor Laboratory Press

9 Levy, S.B., FitzGerald, G.B. and Macone, A.B (1976) N. Engl. L Med. 295, 583-588

10 Modi, R.I., Castilla, L.H., Puskas-Rozsa, S Helling, R.B. and Adams, J. (1992) Cenetics 130, 241-249

11 Lee, S.W. and Edlin, G. (1985) Gene 39, $173-180$

12 Nguyen, T.N.M., Phan, Q.G., Duong, L.P., Bertrand, K.P. and Lenski, R.E. (1989) Mol Biol. Evol. 6, 213-225

13 Modi, R.I., Wilke, C.M., Rosenzweig, R.F. and Adams, 1. (1991) Genetica 84, 195-202

14 Smith, II.W. (1975) Nature 258, 628-630

15 Bouma, J.E. and Lenski, R.E. (1988) Nature $335,351-352$

16 Mendez, B., Tachibana, C. and Levy, S.B. (1980) Plasmid 3,99-108

17 Levy, S.B. (1989) J. Antimicrob. Chemother 24, $1-7$

18 McMurray, L., Petrucci, R.E., Jr and Levy, S.B (1980) Proc. Natl Acad. Sci. USA 77, 3974-3977

19 Brown, J.T. and Roberts, M.C. (1989)

Antimicrob. Agents Chemother, 32, 765-767

20 Speer, B.S., Bedzyk, K.L. and Salyers, A.A. 11991) J. Bacteriol. 173, 176-183

21 Ohnuki, T., Katoh, T., Imanaka, T. and Aiba, S. (1985) J. Bacteriol. 161, 1010-1016

22 Guiney, D.G. Ir. Hasegawa, P. and Davis

C.E. (1984) Plasmid I I, 248-252

23 George, A.M. and Levy, S.B. (1983)

1. Bacteriol, 155, 531-540

24 ives, C.L. and Bott, R.F. $(1989)$

1. Bacteriol. 171, 1801-1810

25 Bertrand, K.P. Postle, K. Wray, L.V., Ir and 
Reznikoff, W.S. (1983) Gene 23, 149-166 26 Unger, B., Klock, G. and Hillen, W. (1984) Nucleic Acids Res. 12, 7693-7703 2: Waters, S., Rogowsky, P., Grinsted, I., Aitenbuchner, J. and Schmitt, R. (1983) Nucleic Acids Res. 11, 6089-6105 2t: Klock, G.B. et al. (1985) /. Bacteriol. 161
$326-332$

29 Curiale, M.S., McMurry, L.M. and Levy, S.B. (1984) J. Bacteriol. 157, 211-217

30 Curiale, M.S. and Levy, S.B. (1982)

J. Bacteriol. 151, 209-215

31 Rubin, R.A. and Levy, S.B. (1990)

J. Bacteriol. 172, 2303-2312
32 Rubin, R.A. and Levy, S.B. (1991) I. Bacteriol. 173, 4503-4509

33 Coleman, D.C., Chopra, I., Shales, S.A., Howe, T.G. and Foster, T.J. (1983) I. Bacteriol. 151, 209-215

34 Rubin, R.A., Levy, S.B., Heinrickson, R.L and Kézdy, F.J. (1990) Gene 87, 7-13

\section{Landscape Ecology of Boreal Forests}

It is becoming increasingly clear that densities and dynamics of various organisms often cannot be understood from the processes occurring within separate habitat pratches. Effects from surrounding areas clso have to be considered; a landscape perspective has to be employed. Habitat mosaics affect diversity and dynamics both in pristine and managed boreal landscapes. There is increasing interest in the landscape ecology of boreal forests and many important processes have been identified as being driven or affected by invironmental heterogeneity. Comparisons between ecological processes in original and managed boreal landscapes are argently needed.

Anyone flying over northern scandinavia would be struck by the egular mosaic below - large, geometric forest blocks, each one very homogeneous with regard to tree spacing and age structure. Those flying over northern Canadian forest areas may encounter a different mosaic with irregular patches consisting of heterogeneous young and old forests, both coniferous and deciduous. Both impressions differ considerably from the common belief that laiga areas are old, closed forests extending continuously towards the horizon.

Such observations illustrate that boreal forests cannot be viewed as one typical habitat; a landscape perspective usually has to be applied to studies of these areas. Original landscape patterns still remain in some remote places but, elsewhere, these have largely been replaced by a distinctly different landscape through the effects of intense forestry. Unlike tropical forests, boreal forest areas are not threatened by loss of land to agri-

Lennart Hansson is at the Dept of Wildlife Ecology, Swedish University of Agricultural Sciences, PO Box 7002, S-750 07 Uppsala, Sweden.

Lennart Hansson

culture, but instead show a tendency to increase in size; and unlike temperate forests, which are often surrounded by farmland or urban environments, boreal forest fragments are usually situated in a matrix of successional forest stages. Many boreal organisms may have adapted to an old landscape mosaic that is now rapidly being replaced with stages fashioned for sustained timber and pulp production. However, we do not know how firm and widespread such adaptations are, as the present boreal biome is still young - in many places only about 10000 years old

Boreal forest organisms might be classified according to their responses to landscape scale; some species may complete their whole life cycle within one well-defined habitat without any interference from outside, while others move between habitats or are affected by larger-scale influences (e.g. predators) from other habitats. We still do not know the relative importance of these two types, but those species affected by landscape composition may be very numerous and presumably increase in proportion with body size; this review will mainly deal with this latter type of organism. However, on a finer scale, managed habitats have become both spatially and temporally more homogeneous through monoculture and this artificial homogeneity will affect almost all organisms. Some consider all changes in habitat structure that affect movement patterns as landscape ecology'

\section{Landscape patterns}

The old boreal landscape was patterned by forest fires, insect outbreaks and storm-felling ${ }^{2-4}$.
Forest fires often affected enormous areas but size distributions were still biased towards smaller patches $^{5}$. Fire free refugia occurred in certain wet or cold localities, such as lake and mire islands or on northern slopes; gap regeneration may have been common in these places.

A managed forest landscape shows a rectangular age distribution, unlike the negative exponential age distribution of forests patterned by forest fires ${ }^{2}$. If similar proportions of the forests are affected annually, then fire-influenced forests will show twice the mean age of managed forests. Many patches of pristine forest (hereafter called old forests) will be several times older than economically mature blocks ready for clearcutting (hereafter called mature forests). Fire frequencies and fire sizes seem to generally decrease towards the forest-tundra transition zone $^{6,7}$. In Quebec, Canada, more than $30 \%$ of boreal forest fires were larger than 1000 ha and less than $35 \%$ were smaller than 50 ha (Ref. 6). Regeneration blocks in Scandinavian managed forests are typically within the range of 10 to $100 \mathrm{ha}$, although larger areas have sometimes been clearcut? ${ }^{7}$ Other silvicultural regeneration methods, such as seeding trees, selective cutting, and so on, are fairly rare today.

The main differences between the old and new mosaic are: that present factory forests lack really old, dying and dead trees and coarse forest floor woody debris (the trees are harvested when the timber increment is negligible); that clearcuts are devoid of the standing dead trees that remain 